Research Article

\title{
Short-Term Gradation Loading Creep Properties and Failure Characteristics of High-Strength Fly Ash Concrete for Underground Engineering
}

\author{
Bing Li $\mathbb{D}^{1},{ }^{1}$ Lianying Zhang $\mathbb{D}^{1},{ }^{1}$ Hai Pu $\mathbb{D}^{2,3}$ Xianbiao Mao ${ }^{2},{ }^{2,3}$ Peitao Qiu ${ }^{1}{ }^{1}$ \\ Zhong Zhao $\mathbb{D}^{1}{ }^{1}$ and Chao Ma $\mathbb{1}^{1}$ \\ ${ }^{1}$ School of Civil Engineering, Xuzhou Institute of Technology, Xuzhou 221008, Jiangsu, China \\ ${ }^{2}$ State Key Laboratory of Geomechanics and Deep Underground Engineering, China University of Mining \& Technology, \\ Xuzhou 221008, Jiangsu, China \\ ${ }^{3}$ School of Mechanics and Civil Engineering, China University of Mining \& Technology, Xuzhou 221008, Jiangsu, China
}

Correspondence should be addressed to Lianying Zhang; zhanglianying@126.com

Received 13 August 2020; Revised 20 November 2020; Accepted 1 December 2020; Published 16 December 2020

Academic Editor: Fengqiang Gong

Copyright $(2020$ Bing Li et al. This is an open access article distributed under the Creative Commons Attribution License, which permits unrestricted use, distribution, and reproduction in any medium, provided the original work is properly cited.

In order to study the short-term creep deformation of high-strength concrete with varying fly ash replacement ratios, concrete samples with $0,20,35$, and $50 \mathrm{wt} \%$ fly ash were tested using an electrohydraulic servocontrolled creep testing system and characterized using scanning electron microscopy after fracturing. Three different creep deformation behaviors were observed over time under different stress levels, namely, decelerating, isokinetic, and accelerating creep, where the creep rate increased with increasing stress. Failure of the samples occurred once isokinetic creep was achieved. The peak stress of the concrete samples exhibited a parabolic trend with increasing fly ash content, where the peak stress in the $0,20,35$, and $50 \mathrm{wt} \%$ samples during shortterm gradation loading creep testing was $13.08 \%, 7.94 \%, 15.14 \%$, and $14.50 \%$ lower, respectively, than the peak stress measured in conventional uniaxial compression testing. The accumulated creep of the samples was reported and can be used as a reference for future studies on the long-term creep characteristics of concrete. The macro- and microscopic failure modes of the fly ash concrete during short-term gradation loading creep under uniaxial compression were brittle cleavage fracturing.

\section{Introduction}

The rapid rise in the global population and economy has led to the depletion of shallow underground resources, and deeper exploration has inevitably increased. In turn, sudden disasters related to underground construction have become more frequent. The deeper underground space is a complicated environment associated with high ground stress, high ground temperature, and high karst water pressure, which pose significant challenges to engineering personnel and scientific researchers [1-3]. For example, deep coal is an important underground resource utilized in various countries, but accidents occur frequently during its mining due to the associated environment, lithology, exploitation, and transformation. Mine walls and roadway supports to control rocks in coal mines should be improved. This development should encompass deep underground geomechanical testing technology, data on the physical and mechanical properties of the rocks, low stress and mining-induced stress field distribution laws, and the deformation and destruction mechanisms of the surrounding rocks. Further, control, support, and reinforcement technologies should be considered [4-7].

Concrete is one of the most widely used building materials, where applications have extended beyond conventional buildings to underground, aquatic, and marine structures. This broad spectrum of applicability is associated with a range of qualitative changes in concrete materials, where factors such as high stress, high corrosion, and high or low temperature play a role. Continued research and 
practical implementation have contributed to the development of novel concrete materials with high strength and high or ultrahigh performance, such as fly ash concrete, slag concrete, and fiber concrete [8-13]. The development of concrete materials and technologies has led to advancements in deep underground space engineering. These scientific and technological research achievements are particularly relevant to mine sidewalls and roadway supports [14-19]. However, the concrete materials used in deep underground engineering must be further improved.

This study aimed to evaluate the short-term creep deformation of high-strength concrete with varying fly ash replacement ratios using the gradation loading test method. The creep mechanical properties and failure characteristics of the concrete samples were determined by analyzing the creep-time curves, peak strength, creep rate, and accumulated creep measurements, as well as macroscopic and microscopic observations after failure. These findings are expected to provide insights that support further engineering applications.

\section{Experimental Program}

2.1. Materials. The cementitious materials used in the experiment were Portland cement and fly ash supplied by two local companies, where the chemical compositions are given in Table 1. River sand was used as the fine aggregate, which had a fineness modulus of 2.8 and an apparent density of $2769 \mathrm{~kg} / \mathrm{m}^{3}$. Crushed limestone was used as the coarse aggregate, which had a particle size of 5 to $20 \mathrm{~mm}$ and an apparent density of $2719 \mathrm{~kg} / \mathrm{m}^{3}$. The polycarboxylate superplasticizer was provided by Zhejiang Wulong Chemical Co. Ltd (China).

2.2. Samples. Concrete samples $(100 \times 100 \times 300 \mathrm{~mm})$ were produced according to the mixing ratios given in Table 2, where the fly ash replacement level $(m)$ was either $0,20,35$, or $50 \mathrm{wt} \%$. A maintenance period of over 90 days was used. Three samples of cement with each fly ash replacement ratio were prepared for the uniaxial compression test and the gradation loading creep test.

2.3. Characterization. The strain gauge was mounted in a procedure that involved of patching, grinding, cleaning, and pasting steps (Figure 1). A strain gauge was mounted to each sample on its two symmetrical sides. Uniaxial compression testing was conducted before the stepwise creep loading test to determine the conventional uniaxial compressive peak strength of concrete with each fly ash replacement ratio (Table 3). An electrohydraulic servocontrolled compression testing machine was used (Changchun Kexin YAS-5000) (Figure 2). The gradation loading test method was used to evaluate creep deformation, where the specimen was loaded at a rate of $3 \mathrm{kN} / \mathrm{s}$ to $30 \%$ of its uniaxial compressive peak strength, held for $30 \mathrm{~min}$, and unloaded. Stepwise compression was followed where the load was increased by $10 \%$ of the uniaxial compressive peak strength, held for $30 \mathrm{~min}$, and unloaded. The process was repeated until the specimen failed. The strain and stress were measured using the strain gauges and pressure sensors.

Scanning electron microscopy (SEM) was used to observe fragments of the concrete samples $(10 \times 10 \times 10 \mathrm{~mm})$ at a consistent distance (about $10 \mathrm{~mm}$ ) from the concrete surface (Figure 3). Analysis was conducted using the TESCAN VGEA3 SEM test system provided by the Civil Structure Laboratory of Xuzhou Institute of Engineering. Before observation, the samples were dried and sprayed with gold (SBC-12 Ion Sputter Coater).

\section{Results and Discussion}

3.1. Creep Deformation under Gradation Loading. The creeptime $(\varepsilon-t)$ curves of concrete with varying fly ash replacement ratios under increasing stress revealed slightly different behavior between the three samples for each fly ash replacement ratio (Figure 4). This indicated that the results are associated with a certain level of discreteness. The creep deformation exhibited three trends at the different stress levels over time, namely, decelerating, isokinetic, and accelerating creep. Decelerating creep was predominantly observed at low stress levels, while isokinetic and accelerating creep became dominant under higher stress just before sample failure.

\subsection{Uniaxial Compressive Peak Strength. The conventional} uniaxial compression peak stress $\left(\sigma_{c 0}\right)$, creep peak stress $\left(\sigma_{c}\right)$, and drop ratio $\left(r=\left(\sigma_{c 0}-\sigma_{c} / \sigma_{c 0}\right)\right)$ of the fly ash concrete with varying replacement ratios $(m)$ are given in Table 2 and Figure 5. The uniaxial compression peak stress values initially increased and subsequently decreased with increasing fly ash replacement. Thus, the trend was fitted according to a parabola, namely, $\sigma_{\mathrm{c} 0}=-154.47 \mathrm{~m}^{2}+68.83 m+58.06$, where $\mathrm{MPa}$ is the unit of $\sigma_{\mathrm{c} 0}$. Specifically, $\sigma_{\mathrm{c} 0}=58.1 \mathrm{MPa}$ at $m=0 \mathrm{wt}$ $\% ; \sigma_{\mathrm{c} 0}=65.5 \mathrm{MPa}$ at $m=20 \mathrm{wt} \%$ (12.74\% increase from $m=0$ wt $\%) ; \sigma_{\mathrm{c} 0}=63.4 \mathrm{MPa}$ at $m=35 \mathrm{wt} \%(9.12 \%$ increase from $m=0 \mathrm{wt} \%)$; and $\sigma_{\mathrm{c} 0}=53.8 \mathrm{MPa}$ at $m=50 \mathrm{wt} \%(7.40 \%$ decrease from $m=0 \mathrm{wt} \%)$. Thus, the maximum uniaxial compression peak stress was achieved in concrete with a fly ash replacement ratio between 20 and $35 \mathrm{wt} \%$, where the fitted parabola indicated the value was $22.3 \mathrm{wt} \%$.

The creep peak stress exhibited a similar parabolic trend with increasing fly ash replacement ratio and was fitted as $\sigma_{\mathrm{c}}=-165.66 m^{2}+71.64 m+50.93$, where MPa is the unit of $\sigma_{\mathrm{c}}$. Specifically, $\sigma_{\mathrm{c}}=50.5 \mathrm{MPa}$ at $m=0 \mathrm{wt} \% ; \sigma_{\mathrm{c} 0}=60.3 \mathrm{MPa}$ at $m=20 \quad \mathrm{wt} \% \quad(19.41 \%$ increase from $m=0 \quad \mathrm{wt} \%)$; $\sigma_{\mathrm{c} 0}=53.8 \mathrm{MPa}$ at $m=35 \mathrm{wt} \%(6.53 \%$ increase from $m=0 \mathrm{wt}$ $\%)$; and $\sigma_{\mathrm{c} 0}=46.0 \mathrm{MPa}$ at $m=50 \mathrm{wt} \%$ (8.91 \% increase from $m=0 \mathrm{wt} \%)$. Thus, the maximum creep peak stress was achieved at a fly ash replacement ratio between 20 and $35 \mathrm{wt}$ $\%$, namely, $21.6 \mathrm{wt} \%$ according to the fitted parabolic model. The conventional uniaxial compression peak stress and creep peak stress values exhibited very similar parabolic trends. Thus, optimization of the fly ash concrete for a large conventional uniaxial compression peak stress would simultaneously lead to a large creep peak stress. 
TABle 1: Chemical composition of the cementitious materials.

\begin{tabular}{lcccccccc}
\hline Materials & $\mathrm{SiO}_{2}(\%)$ & $\mathrm{Al}_{2} \mathrm{O}_{3}(\%)$ & $\mathrm{Fe}_{2} \mathrm{O}_{3}(\%)$ & $\mathrm{CaO}(\%)$ & $\mathrm{MgO}(\%)$ & $\mathrm{Na}_{2} \mathrm{O}(\%)$ & $\mathrm{K}_{2} \mathrm{O}(\%)$ & $\mathrm{SO}_{3}(\%)$ \\
\hline Cement & 21.6 & 4.13 & 4.57 & 64.44 & 1.06 & 0.11 & 0.56 & 1.74 \\
Fly ash & 54.9 & 25.8 & 6.9 & 8.7 & 1.8 & 0.3 & 0.1 & 0.6 \\
\hline
\end{tabular}

TABLE 2: Mixing ratios of the concrete.

\begin{tabular}{lcccccc}
\hline Fly ash content $(\mathrm{wt} \%)$ & Fly ash $\left(\mathrm{kg} / \mathrm{m}^{3}\right)$ & Cement $\left(\mathrm{kg} / \mathrm{m}^{3}\right)$ & Sand $\left(\mathrm{kg} / \mathrm{m}^{3}\right)$ & Stone $\left(\mathrm{kg} / \mathrm{m}^{3}\right)$ & Water-cement ratio & Water $\left(\mathrm{kg} / \mathrm{m}^{3}\right)$ \\
\hline 0.0 & 0.0 & 453.0 & 740.0 & 1112.0 & 0.32 & 145.0 \\
20.0 & 91.0 & 362.0 & 740.0 & 1112.0 & 0.32 & 145.0 \\
35.0 & 159.0 & 294.0 & 740.0 & 1112.0 & 0.32 & 145.0 \\
50.0 & 226.5 & 226.5 & 740.0 & 1112.0 & 0.32 & 145.0 \\
\hline
\end{tabular}

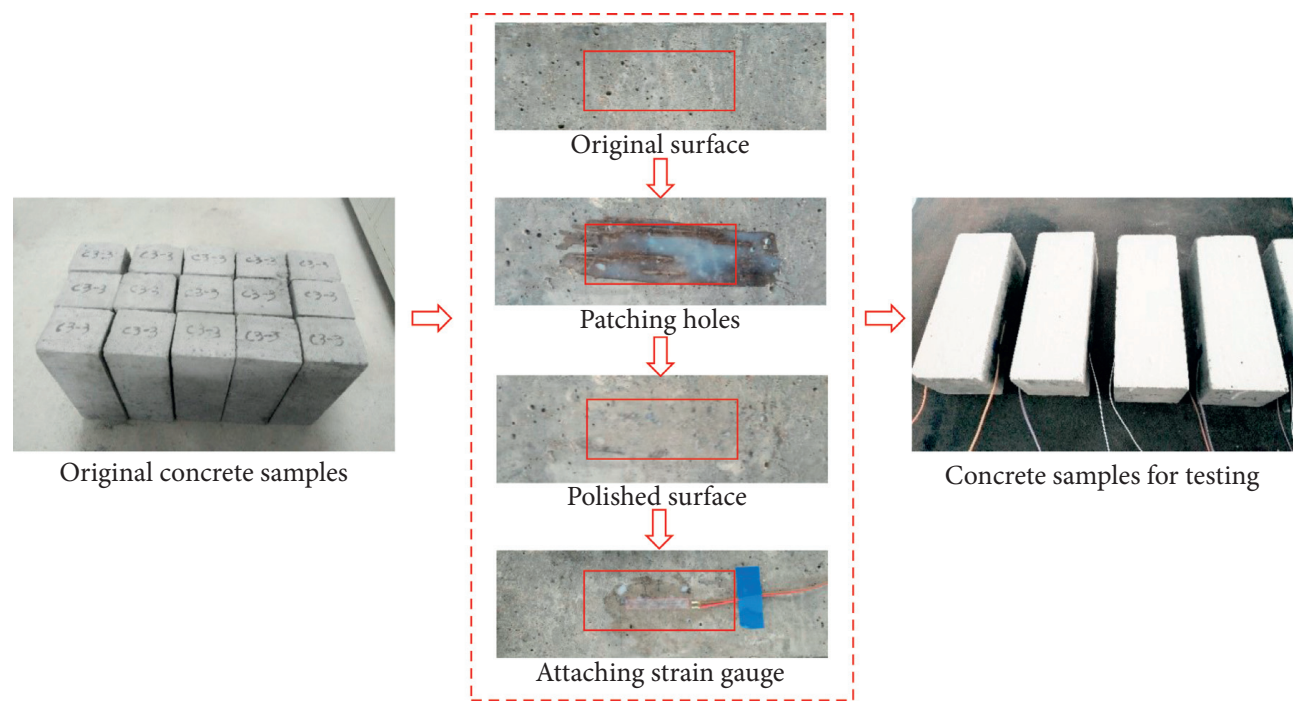

FIGURE 1: Mounting of strain gauges on the concrete samples.

TABle 3: Creep peak stress $\left(\sigma_{\mathrm{c}}\right)$ and conventional uniaxial compression peak stress $\left(\sigma_{\mathrm{c} 0}\right)$ of concrete with different fly ash replacement ratios $(m)$.

\begin{tabular}{|c|c|c|c|c|c|}
\hline \multicolumn{2}{|l|}{$m($ wt $\%)$} & \multirow{2}{*}{$\begin{array}{c}0 \\
58.1\end{array}$} & \multirow{2}{*}{$\begin{array}{c}20 \\
65.5\end{array}$} & \multirow{2}{*}{$\begin{array}{c}35 \\
63.4\end{array}$} & \multirow{2}{*}{$\begin{array}{c}50 \\
53.8\end{array}$} \\
\hline $\begin{array}{l}\text { Axial compression } \\
\text { test }\end{array}$ & $\sigma_{\mathrm{c} 0}(\mathrm{MPa})$ & & & & \\
\hline $\begin{array}{l}\text { Gradation loading } \\
\text { creep test }\end{array}$ & $\sigma_{\mathrm{c}}(\mathrm{MPa})$ & 50.5 & 60.3 & 53.8 & 46.0 \\
\hline Drop ratio $\left(r=\left(\sigma_{\mathrm{c}}\right.\right.$ & $\left.\left.0-\sigma_{\mathrm{c}}\right) / \sigma_{\mathrm{c} 0}\right)$ & $13.08 \%$ & $7.94 \%$ & $15.14 \%$ & $14.50 \%$ \\
\hline
\end{tabular}

The drop ratios were $13.08 \%, 7.94 \%, 15.14 \%$, and $14.50 \%$ at fly ash replacement ratios of $0,20,35$, and $50 \mathrm{wt} \%$. Thus, creep and fly ash replacement had a dual influence on the conventional uniaxial compression peak stress. Creep caused a reduction in uniaxial compression peak stress, where a fly ash ratio of up to $21.6 \mathrm{wt} \%$ fly ash led to an improvement in the uniaxial compression peak stress of concrete. However, even the optimal level of $21.6 \mathrm{wt} \% \mathrm{did}$ not compensate for the negative influence of creep deformation. When the fly ash replacement ratio was over $21.6 \mathrm{wt}$ $\%$, its positive effect was weakened.
3.3. Creep Rate. Specific samples were selected for the separation of the strain under varied stress levels, namely, sample 1 for $0 \mathrm{wt} \%$ fly ash (Figure 4(a)), sample 2 for $20 \mathrm{wt} \%$ fly ash (Figure 4(b)), sample 2 for $35 \mathrm{wt} \%$ fly ash (Figure 4(c)), and sample 2 for $50 \mathrm{wt} \%$ fly ash (Figure 4(d)). The instant strain was deducted from the corresponding stress level to give the creep strain-time $\left(\varepsilon_{\mathrm{cp}}-t\right)$ curves (Figure 6). The strain at concrete failure (accelerating creep stage) was not calculated. Overall, the concrete exhibited different creep strain-time curves under different stress levels. Specifically, decelerating creep occurred under low stress, resulting in a relatively small creep value. A rise in stress level led to an increase in the creep value and creep rate. At a certain point, often near the peak stress of the concrete, decelerating and isokinetic creep was observed, where the failure occurred once isokinetic creep began.

The decelerating creep stage (Figure $7(\mathrm{a})$ ) and the subsequent decelerating/isokinetic creep stage (Figure $8(a)$ ) presented in Figure 6 were used for exponential function fitting in Figures 7(b) and 8(b), respectively, based on fitting functions (1) and (2). The creep rate $\left(d \varepsilon_{\mathrm{cp}}\right)$ was calculated based on derivatization of the fitting parameters given in 


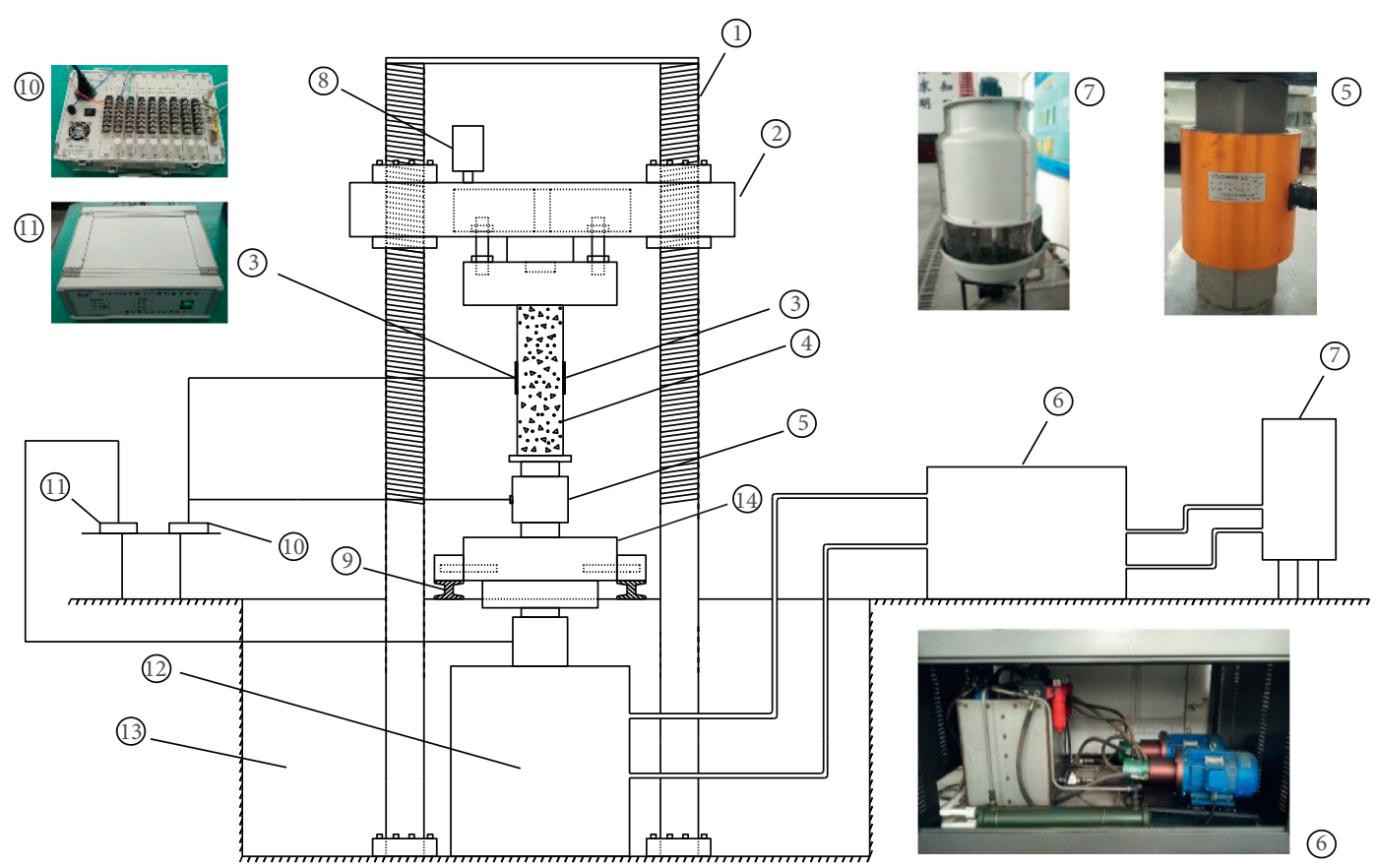

Figure 2: Electrohydraulic servocontrolled creep test system with the following components: (1) guide screw, (2) bearing plate, (3) strain gauge, (4) concrete, (5) pressure transducer, (6) oil pump system, (7) cooling tower, (8) electric machinery, (9) track, (10) strain collection device, (11) controller, (12) power device, (13) underground space, and (14) bearing plate.

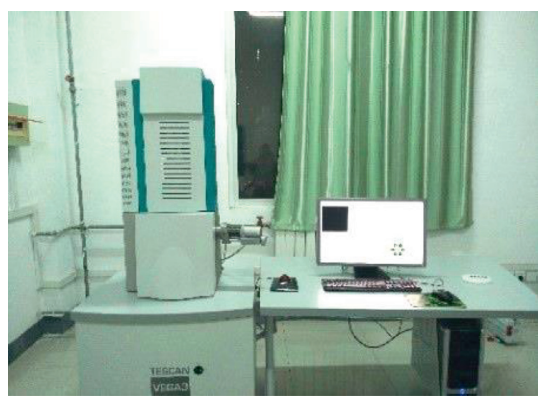

(a)

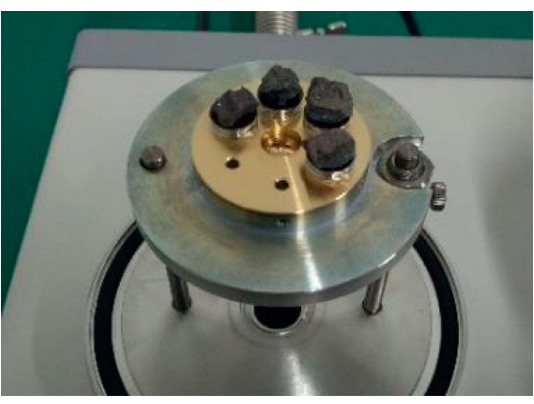

(b)

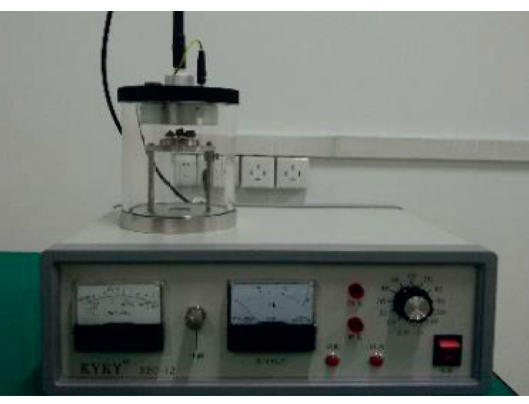

(c)

FIGURE 3: SEM analysis of the concrete samples. (a) Scanning electron microscope. (b) Samples for analysis. (c) Gold spraying equipment.

Tables 4 and 5. The fitted values were very similar to the experimental values:

$$
\begin{aligned}
& \varepsilon_{\mathrm{cp}}=C_{1}+A_{1} e^{-t / B_{1}}, \\
& \varepsilon_{\mathrm{cp}}=C_{2}+A_{2} t .
\end{aligned}
$$

The creep rate-time $\left(d \varepsilon_{\mathrm{cp}}-t\right)$ curves for Figures $7(\mathrm{a})$ and $8(\mathrm{a})$ are given in Figures 9(a) and 9(b), respectively. The decelerating creep stage was associated with a gradual decrease in creep rate over time until reaching a rate of zero. The initial creep rate of the concrete with fly ash was significantly smaller than that with no fly ash replacement. However, this difference between the groups gradually decreased over time. The decelerating/isokinetic creep stage exhibited an initial decrease in creep rate over time that was rapid in the concrete with fly ash replacement ratios of 0 and
$50 \mathrm{wt} \%$ and relatively slow at 20 and $35 \mathrm{wt} \%$. The concrete samples eventually entered the isokinetic creep stage near the time of failure. The $20 \mathrm{wt} \%$ fly ash concrete exhibited the highest creep rate, followed by 35,50 , and $0 \mathrm{wt} \%$ (lowest), where the creep rate at 50 and $0 \mathrm{wt} \%$ was very similar.

3.4. Accumulated Creep. The accumulated creep $\left(\varepsilon_{\mathrm{cp}+}\right)$ was calculated as the creep generated at a specific stress level $\left(\sigma_{\mathrm{sp}}\right)$ plus the creep generated at all previous stress levels (Table 6 and Figure 10). The accumulated creep of the concrete mixed with fly ash increased with increasing stress, where two stages were observed. The accumulated creep increased slowly as stress increased below $40 \mathrm{MPa}$ and began to rise sharply as the stress exceeded $40 \mathrm{MPa}$.

At stress below $40 \mathrm{MPa}$, the accumulated creep values were smaller in the concrete mixed with fly ash than the 


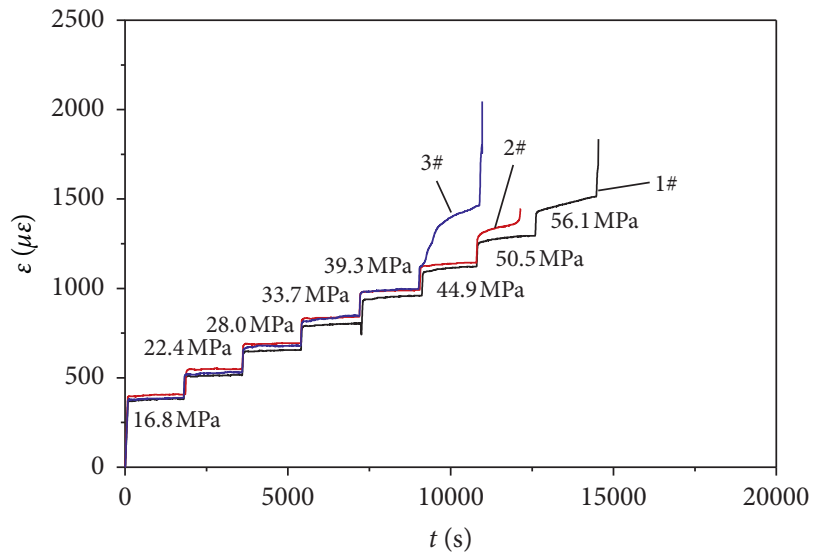

(a)

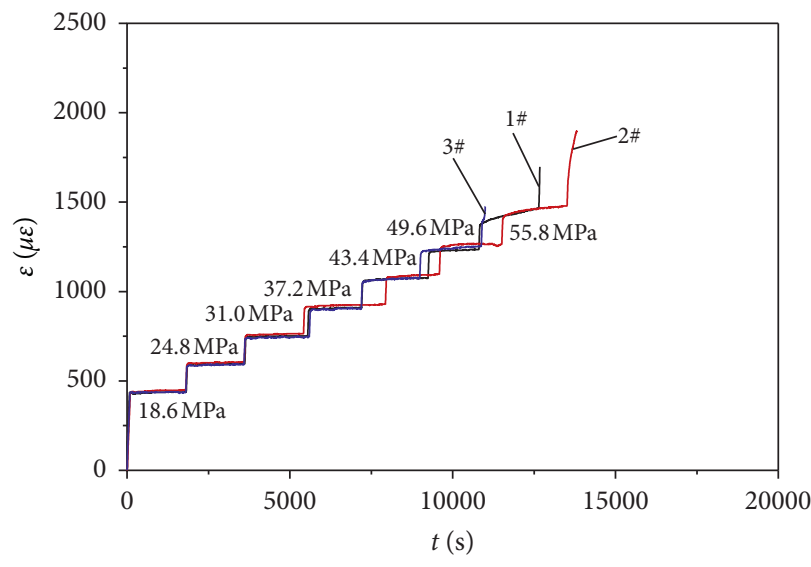

(c)

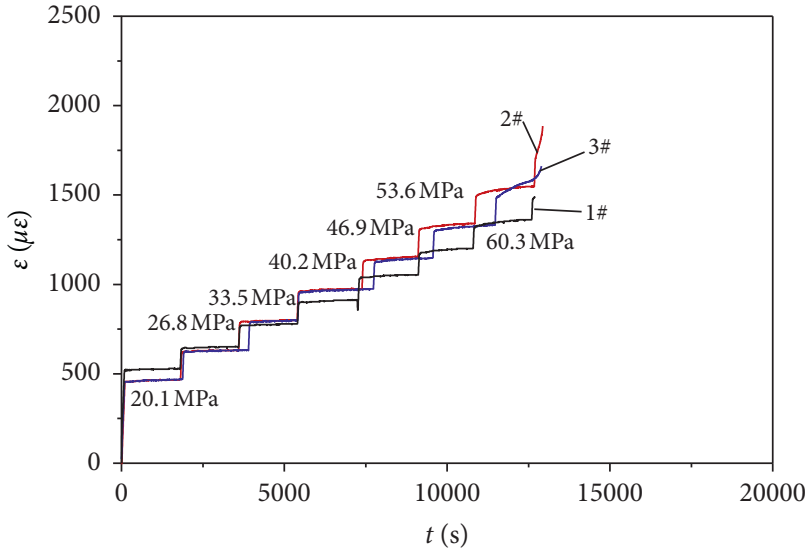

(b)

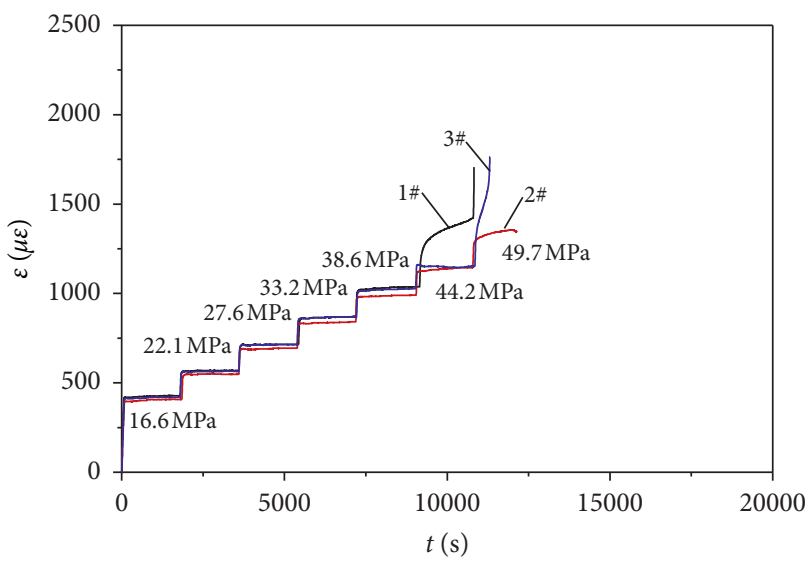

(d)

FiguRe 4: Creep-time $\left(\varepsilon_{\mathrm{cp}}-t\right)$ curves of concrete mixed with fly ash replacement ratios of (a) 0 , (b) 20 , (c) 35 , and (d) 50 wt $\%$ during gradation loading.

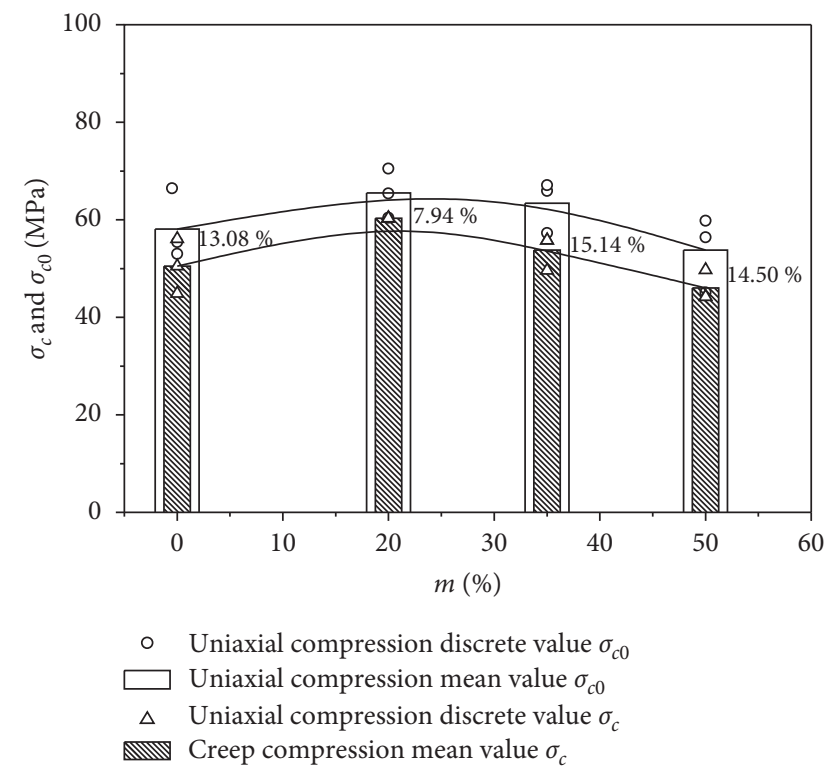

Figure 5: Creep peak stress $\left(\sigma_{\mathrm{c}}\right)$ and conventional uniaxial compression peak stress $\left(\sigma_{\mathrm{c} 0}\right)$ of concrete with different fly ash replacement ratios. concrete without fly ash. As the stress increased further, significant variations in the accumulated creep were observed among the various fly ash concrete groups, but the values were consistently lower than that of concrete without fly ash.

Fly ash replacement led to lower accumulated creep due to the improved antideformation properties of the concrete, where the degree of improvement was related to the fly ash replacement ratio. Specifically, the maximum improvement was observed at $20 \mathrm{wt} \%$ fly ash, after which it began to decrease in the 35 and 50 wt $\%$ fly ash concrete. The maximum accumulated creep of the concrete with $20 \mathrm{wt} \%$ fly ash was $33 \%$ lower than that of the concrete without fly ash. Similar results have been reported by Ghosh and Timusk [20], Huang et al [21]. However, these studies were based on short-term creep testing over a longer time. Therefore, the accumulated creep values presented in this study can be used as a reference for further research on the long-term creep properties of concrete.

3.5. Failure Characteristics. The macroscopic failure modes of fly ash concrete due to short-term gradation loading creep under uniaxial compression are shown in Figure 11. 


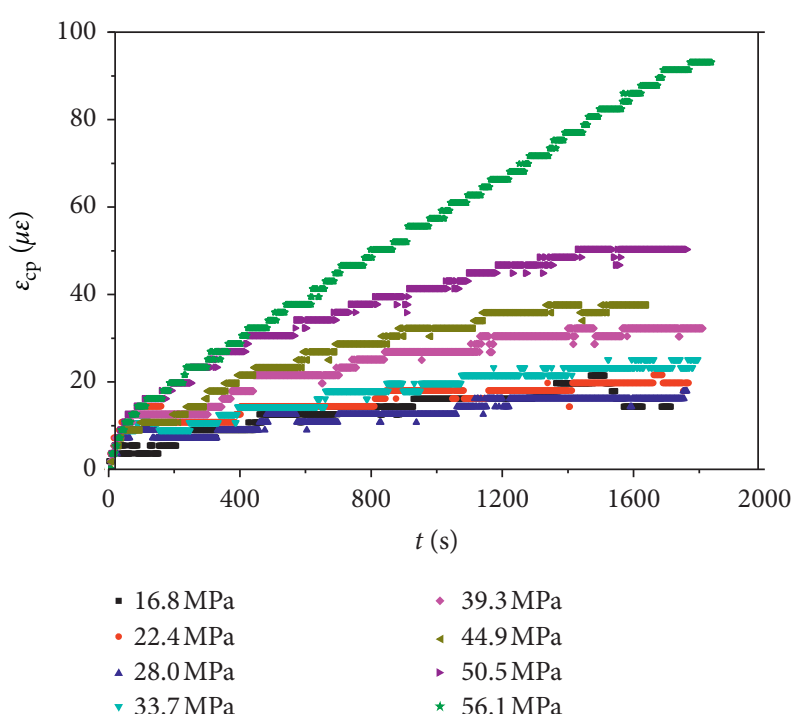

(a)

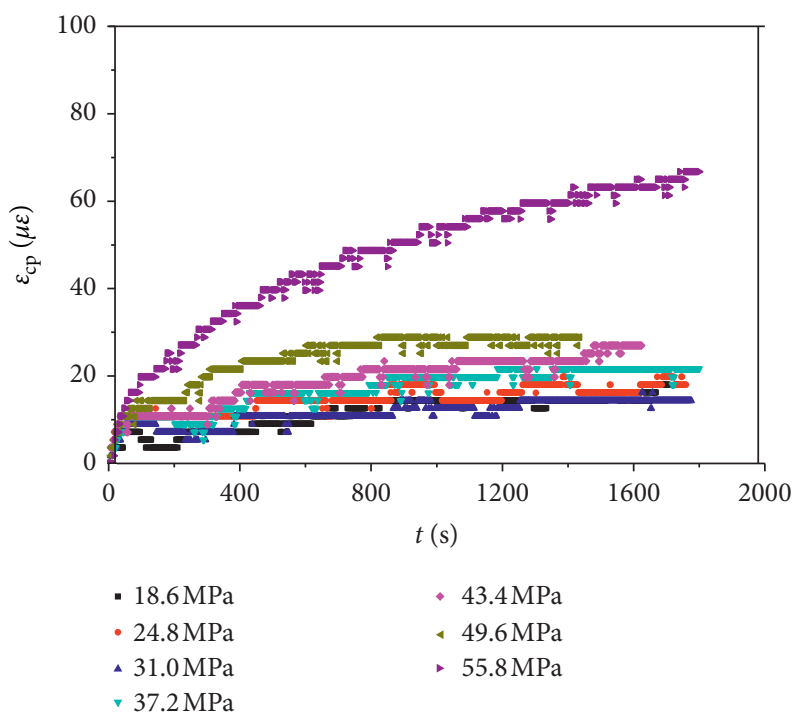

(c)

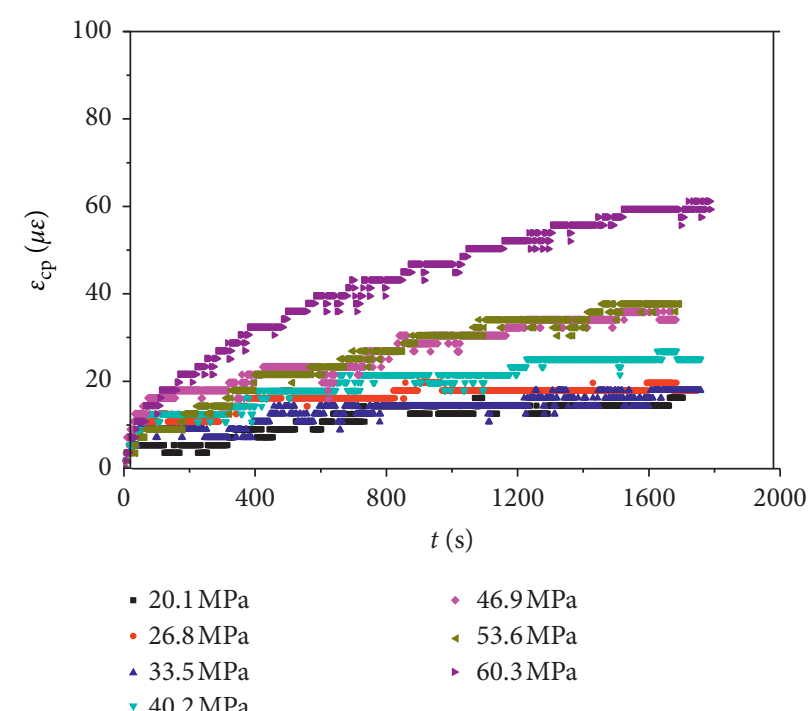

(b)

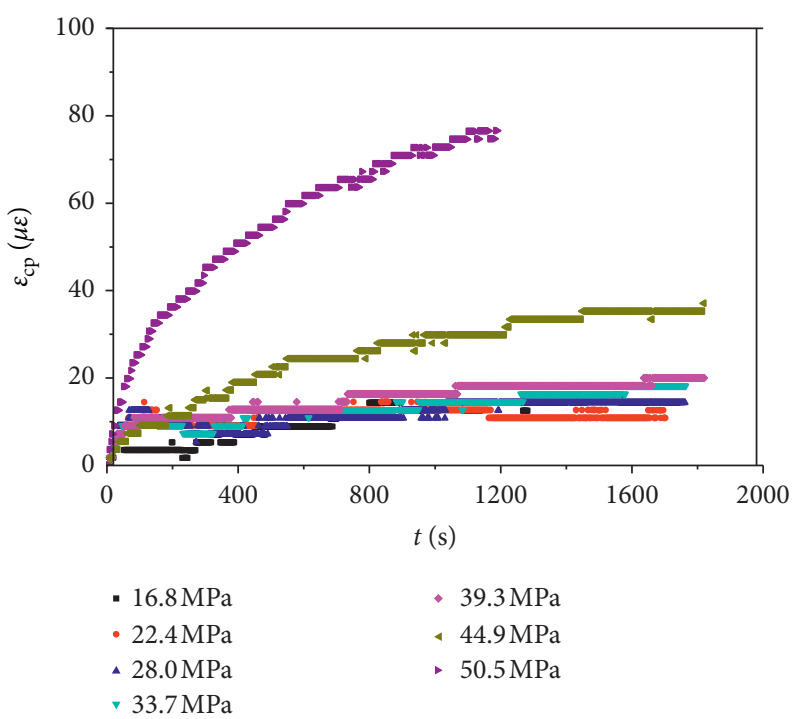

(d)

FiguRE 6: Creep strain-time curves $\left(\varepsilon_{\mathrm{cp}}-t\right)$ of concrete with fly ash replacement ratios of (a) 0 , (b) 20 , (c) 35 , and (d) 50 wt $\%$ under different stress levels.

The samples were largely intact after gradation loading creep failure and exhibited an obvious fractured surface with a few broken pieces. The failure modes were predominantly either oblique section rupture failure, axial direction separation failure, or combined failure. During gradation loading creep testing, the samples exhibited instant failure characterized by a clear loud sound and a small number of broken pieces. These brittle rupture characteristics led to difficulty in observing the generation and evolution of cracks before failure.

SEM was used to evaluate the microscopic rupture characteristics of the concrete samples with different fly ash replacement ratios (Figure 12). Most of the fly ash particles in the concrete with 20 and $35 \mathrm{wt} \%$ fly ash participated in secondary hydration reflection, where the fracture surface was flat and tight. This microstructure contributed to the superior performance compared to concrete without fly ash. The concrete with $50 \mathrm{wt} \%$ fly ash exhibited unhydrated fly ash particles and a relatively rough fracture surface.

SEM was used to evaluate the appearance of the fractures in the concrete with varying fly ash replacement ratios (Figure 13). The concrete with no fly ash replacement exhibited semispherical fracturing along the crystals and step-form fracturing through the crystals. These are brittle fracturing modes. The concrete with $20 \mathrm{wt} \%$ fly ash also exhibited brittle step-form fractures through the crystals, while the $35 \mathrm{wt} \%$ sample exhibited both stackedform fracturing through the crystals and secondary cracks through and along the crystals, both with brittle fracture 


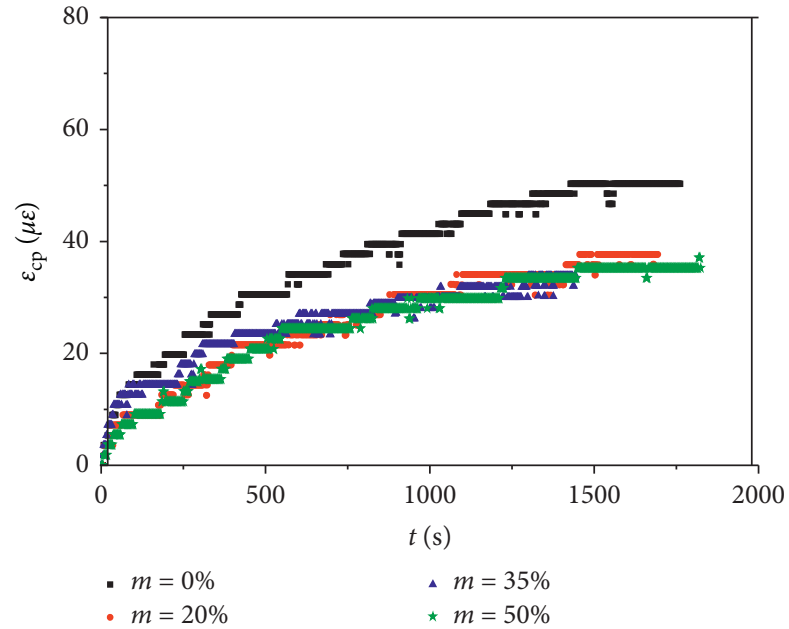

(a)

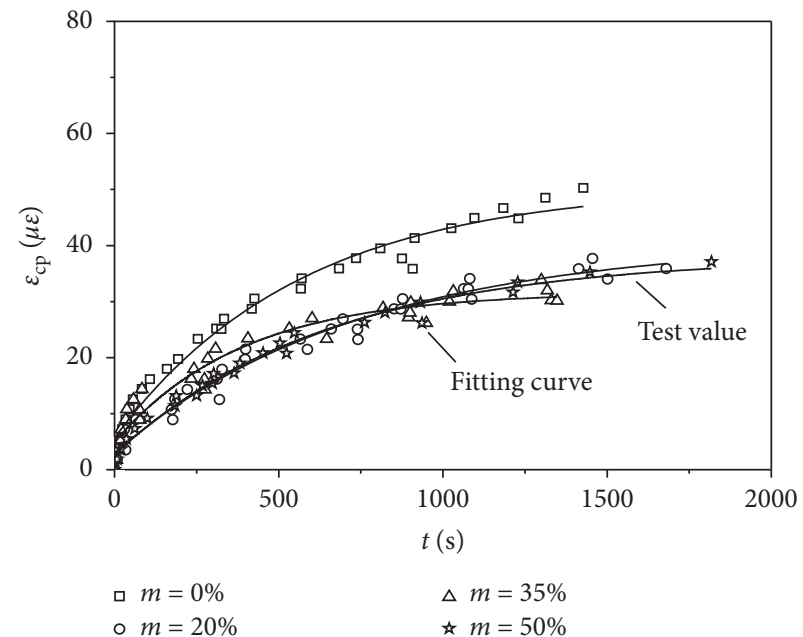

(b)

FIGURE 7: Experimental and fitted creep-stain curves of concrete with various fly ash replacement ratios $(m)$ during the decelerating creep stage.

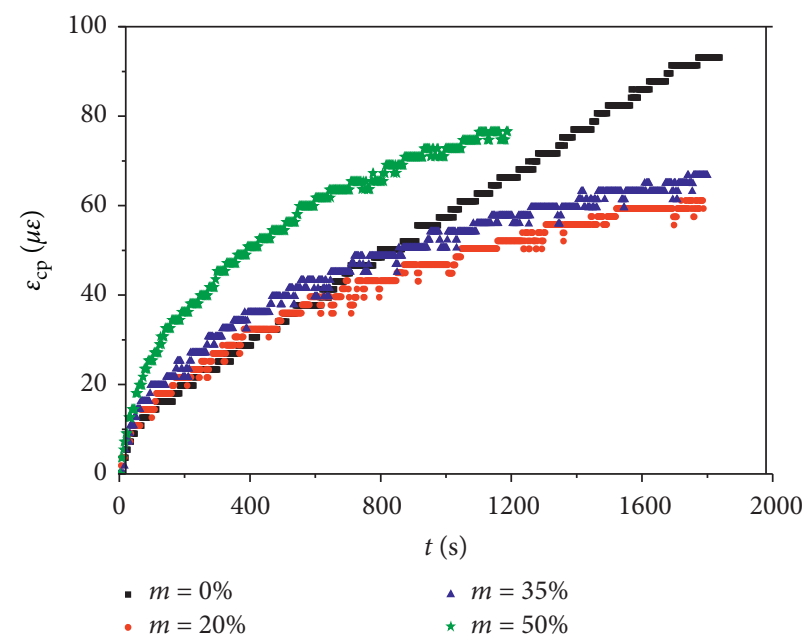

(a)

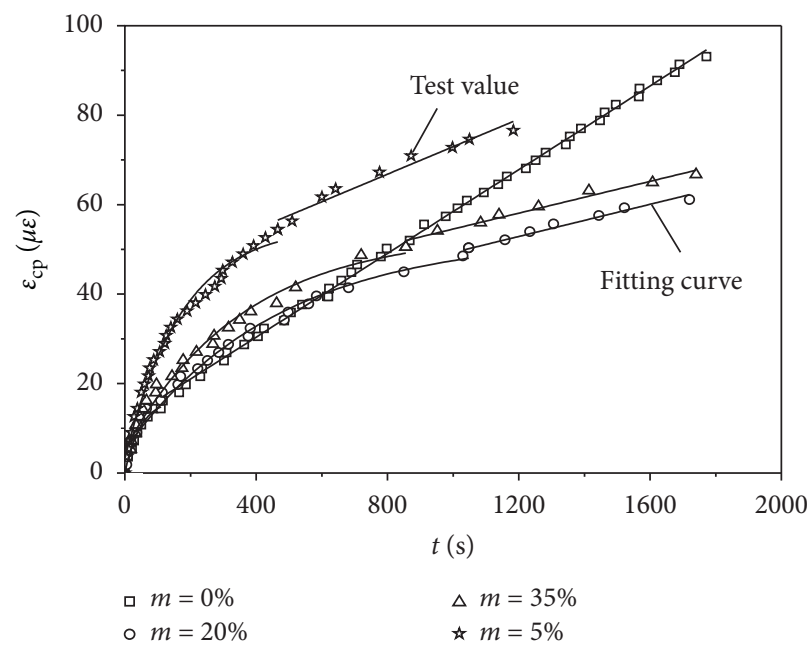

(b)

FIGURE 8: Experimental and fitted creep-stain curves of concrete with various fly ash replacement ratios $(m)$ during the decelerating/ isokinetic creep stage.

TABLE 4: Fitting parameters of concrete with various fly ash replacement ratios during the decelerating creep stage.

\begin{tabular}{lcccc}
\hline \multirow{2}{*}{ Parameter } & \multicolumn{3}{c}{ Fly ash content $($ wt $\%)$} \\
& 0 (stress = 50.5 MPa) & 20 (stress = 53.6 MPa) & $35($ stress = 49.6 MPa) & $50($ stress = 44.9 MPa) \\
\hline$A_{1}$ & -44.91 & -37.72 & -26.76 & -35.33 \\
$B_{1}$ & 566.60 & 746.85 & 358.96 & 646.67 \\
$C_{1}$ & 50.57 & 40.74 & 31.63 & 38.02 \\
\hline
\end{tabular}

TABLE 5: Fitting parameters of concrete with various fly ash replacement ratios during the decelerating/isokinetic creep stage.

\begin{tabular}{lcccc}
\hline \multirow{2}{*}{ Parameter } & \multicolumn{3}{c}{ Fly ash content $($ wt $\%)$} \\
& 0 (stress = 56.1 MPa) & $20($ stress = 60.3 MPa) & $35($ stress = 55.8 MPa) & $50($ stress = 50.5 MPa) \\
\hline$A_{1}$ & -16.60 & -47.78 & -48.36 & -52.09 \\
$B_{1}$ & 49.32 & 456.68 & 361.45 & 175.40 \\
$C_{1}$ & 16.60 & 53.06 & 53.68 & 55.35 \\
$A_{2}$ & 0.047 & 0.018 & 0.018 & 0.031 \\
$C_{2}$ & 11.65 & 31.31 & 36.79 & 42.19 \\
\hline
\end{tabular}




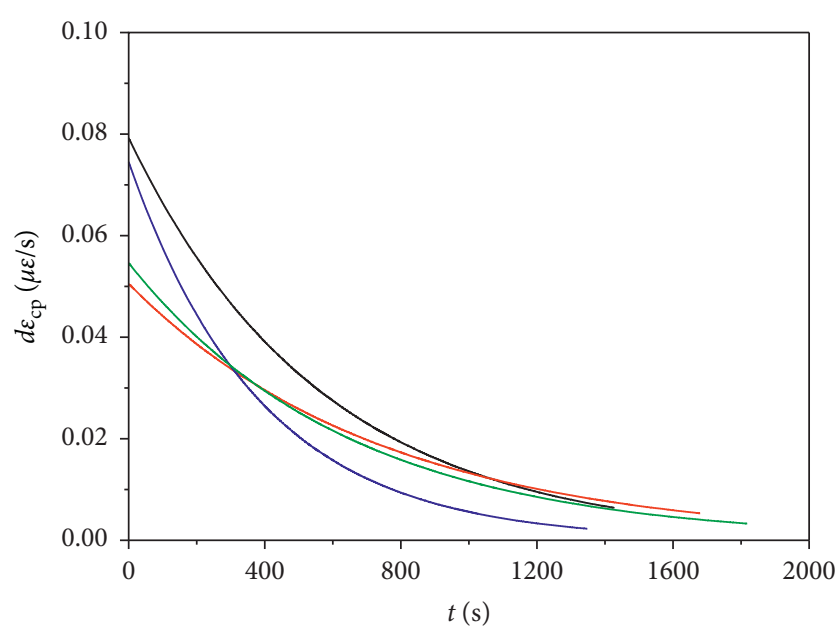

$\begin{array}{ll}-m=0 \% & -m=35 \% \\ -m=20 \% & -m=50 \%\end{array}$

(a)

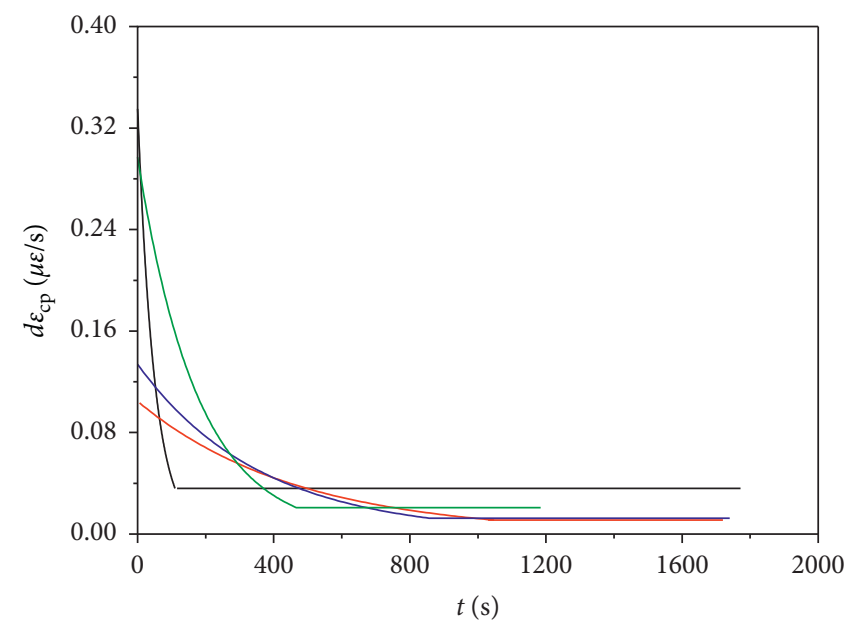

$-m=0 \%$

$m=20 \%$ $-m=35 \%$

$m=50 \%$

(b)

FIGURE 9: Creep rate-time $\left(d \varepsilon_{\mathrm{cp}}-t\right)$ curves of concrete with various fly ash replacement ratios $(m)$ during the (a) decelerating and (b) decelerating/ isokinetic creep stages.

TABLE 6: Accumulated creep $\left(\varepsilon_{\mathrm{cp}+}\right)$ of concrete with various fly ash replacement ratios $(m)$ at different stress levels $\left(\sigma_{\mathrm{sp}}\right)$.

\begin{tabular}{|c|c|c|c|c|c|c|c|c|}
\hline$m=0 \mathrm{wt} \%$ & $\sigma_{\text {sp }}(\mathrm{MPa})$ & $\begin{array}{c}16.8 \\
9.0\end{array}$ & 22.4 & $\begin{array}{l}28.0 \\
35.9\end{array}$ & $\begin{array}{l}33.7 \\
56.9\end{array}$ & $\begin{array}{l}39.3 \\
80.8\end{array}$ & $\begin{array}{c}44.9 \\
144.8\end{array}$ & $\begin{array}{c}50.5 \\
207.4\end{array}$ \\
\hline \multirow{2}{*}{$m=20 \mathrm{wt} \%$} & $\sigma_{\mathrm{sp}}(\mathrm{MPa})$ & 20.1 & 26.8 & 33.5 & 40.2 & 46.9 & 53.6 & 60.3 \\
\hline & $\varepsilon_{\mathrm{cp}}+(\mu \varepsilon)$ & 7.5 & 17.6 & 28.3 & 42.6 & 62.1 & 89.5 & 138.6 \\
\hline \multirow{2}{*}{$m=35 \mathrm{wt} \%$} & $\sigma_{\mathrm{sp}}(\mathrm{MPa})$ & 18.6 & 24.8 & 31.0 & 37.2 & 43.4 & 49.6 & 55.8 \\
\hline & $\varepsilon_{\mathrm{cp}}+(\mu \varepsilon)$ & 8.6 & 16.7 & 26.3 & 39.9 & 58.8 & 80.2 & 140.5 \\
\hline \multirow{2}{*}{$m=50 \mathrm{wt} \%$} & $\sigma_{\mathrm{sp}}(\mathrm{MPa})$ & 16.6 & 22.1 & 27.6 & 33.2 & 38.6 & 44.2 & - \\
\hline & $\varepsilon_{\mathrm{cp}}+(\mu \varepsilon)$ & 3.8 & 8.6 & 14.0 & 23.5 & 38.5 & 96.5 & - \\
\hline
\end{tabular}

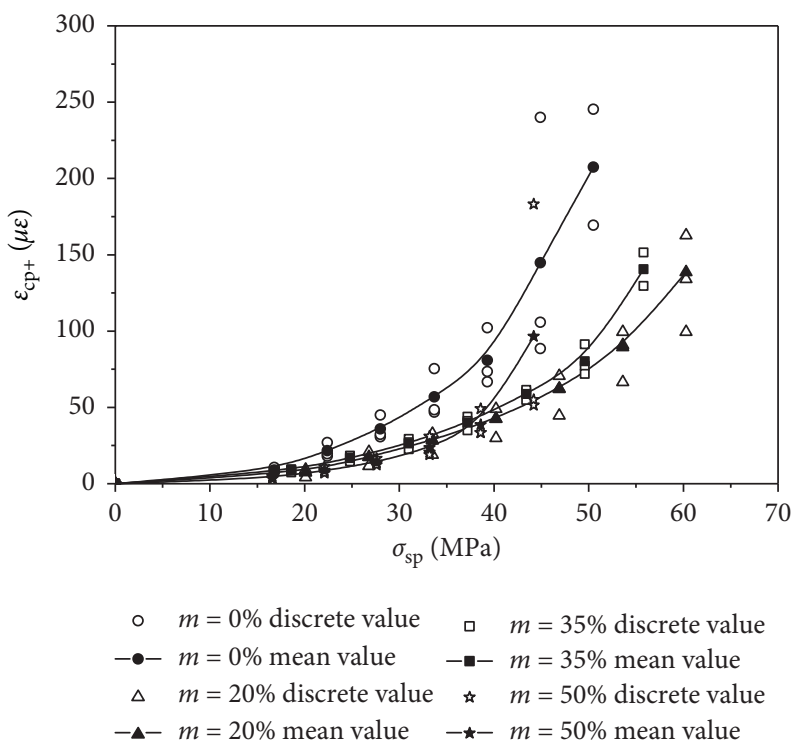

Figure 10: Accumulated creep-stress $\left(\varepsilon_{\mathrm{cp}+}{ }^{-} \sigma_{\mathrm{sp}}\right)$ curves of concrete with various fly ash replacement ratios $(m)$. 


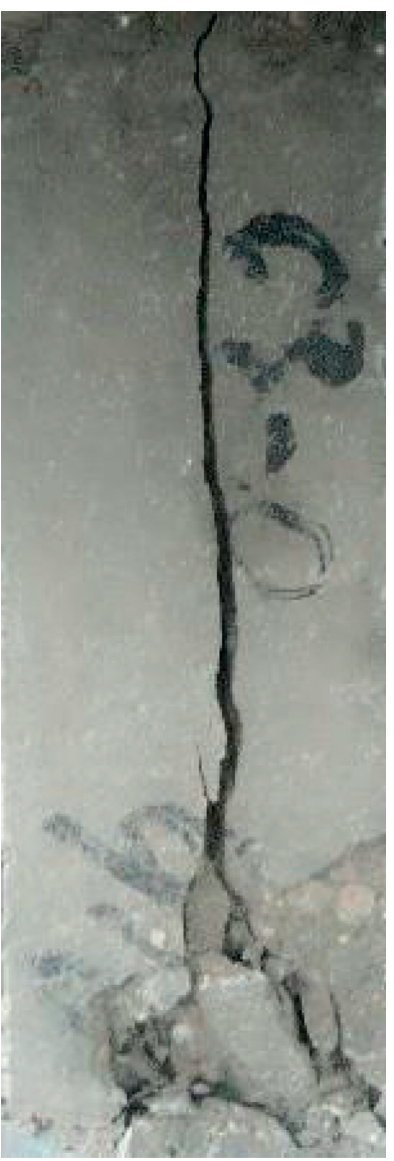

(a)

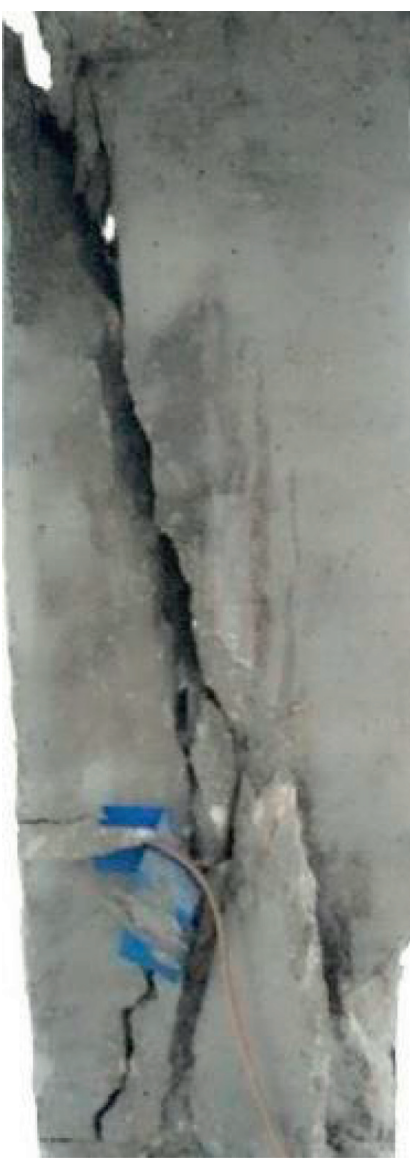

(b)

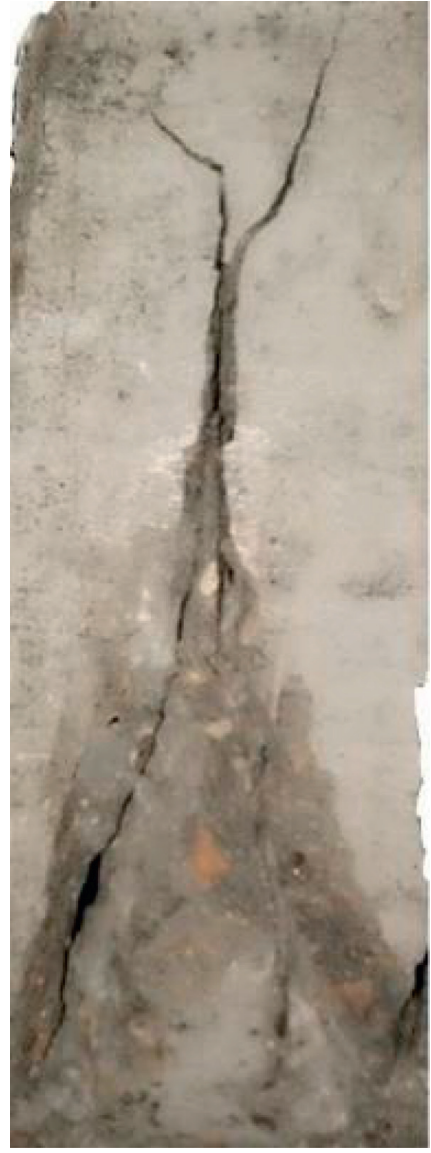

(c)

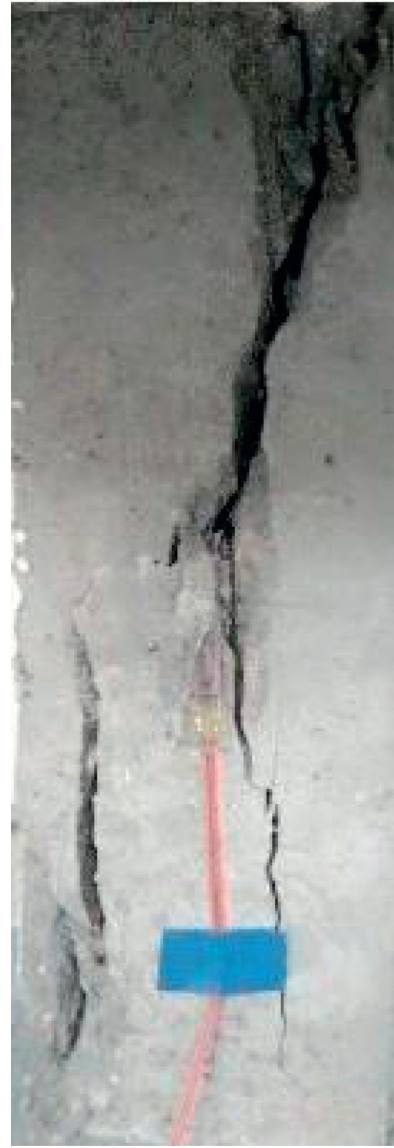

(d)

Figure 11: Failure modes of concrete with fly ash replacement ratios of (a) 0, (b) 20, (c) 35, and (d) 50 wt\% under creep uniaxial compression.

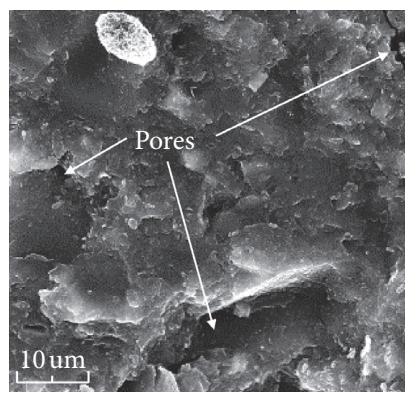

(a)

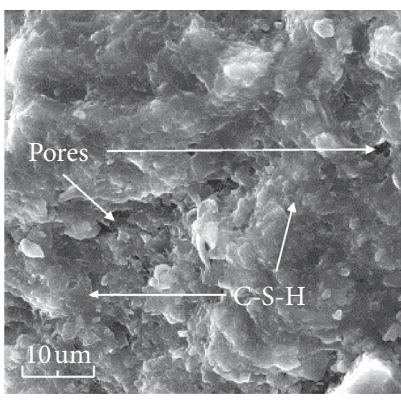

(b)

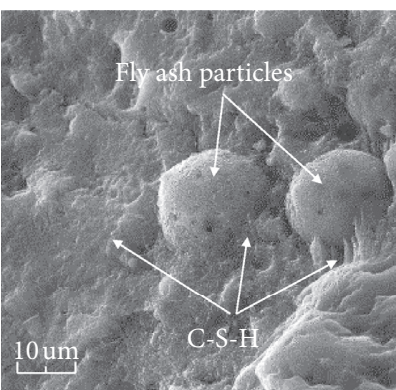

(c)

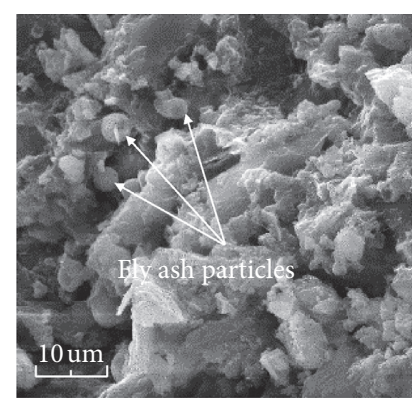

(d)

Figure 12: Microscopic rupture characteristics of concrete with fly ash replacement ratios of (a) 0, (b) 20, (c) 35, and (d) 50 wt\%.

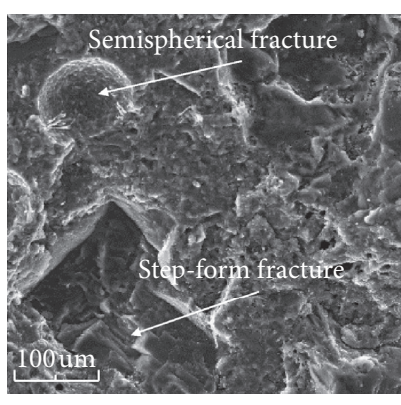

(a)

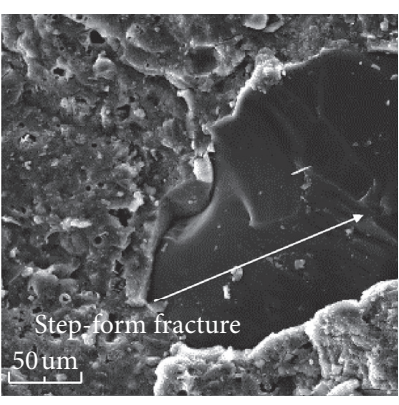

(b)

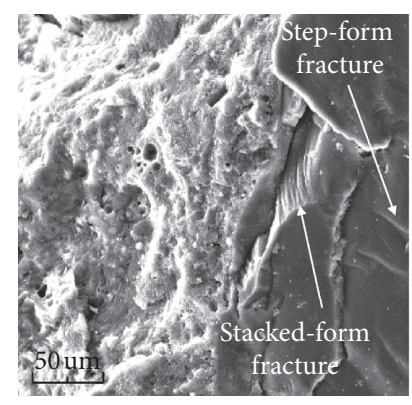

(c)

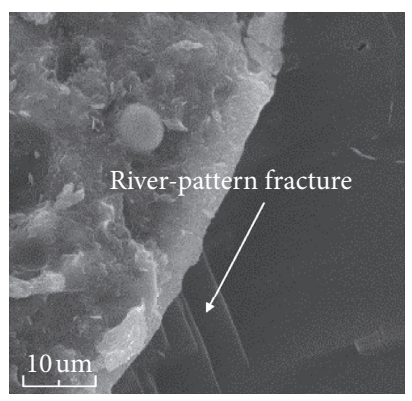

(d)

Figure 13: SEM images of the fracture morphologies of concrete with fly ash replacement ratios of (a) 0 , (b) 20 , (c) 35 , and (d) 50 wt\%. 
characteristics. The concrete with $50 \mathrm{wt} \%$ fly ash underwent brittle river-pattern fracturing through the crystals. Thus, all of the fracturing modes in the concrete with and without fly ash replacement were cleavage fractures with brittle characteristics.

\section{Conclusions}

The mechanical properties of concrete related to short-term gradation loading creep were evaluated at various fly ash replacement levels $(0,20,35$, and $50 \mathrm{wt} \%)$ after 90 days of curing. Creep has exhibited three main behaviors with time under different stress levels, namely, decelerating, isokinetic, and accelerating creep. The creep rate of the concrete increased with increasing stress levels, where the failure occurred once isokinetic creep was reached.

The peak stress of the concrete with fly ash replacement during short-term gradation loading creep testing exhibited a similar parabolic trend to that observed during conventional uniaxial compression testing. The peak stress of the concrete with $0,20,35$, and $50 \mathrm{wt} \%$ fly ash during short-term gradation loading creep testing was $13.08 \%, 7.94 \%, 15.14 \%$, and $14.50 \%$ lower, respectively, than the peak stress recorded during conventional uniaxial compression testing. The accumulated creep values reported in this study can be used as a reference value for further studies on the long-term creep characteristics of concrete.

The microscopic failure characteristics of the fly ash concrete during short-term gradation loading creep under uniaxial compression were attributed to cleavage fractures with brittle fracture characteristics, which was reflected in the macroscopic failure form.

\section{Data Availability}

The data used to support the findings of this study are available from the corresponding author upon request.

\section{Conflicts of Interest}

The authors declare that there are no conflicts of interest regarding the publication of this article.

\section{Acknowledgments}

The authors gratefully acknowledge the financial support for this work, provided by the National Natural Science Foundation 52074240 and 51974296), the Research Project of “333 Project” in Jiangsu Province of China (BRA2019236), the General Program of Chinese National Building Materials Industry Technology Innovation (2016-Z-7 and 2016-Z-8), the Natural Science Research Project of Higher Education of Jiangsu (General Program 16KJB560017 and 18KJB560019), the Science and Technology Project of the Jiangsu Department of Housing and Urban-Rural Construction (2017ZD163), the Research Program of Xuzhou Institute of Technology (XKY2018131), the Xuzhou Key Research and Development Program (Nos. KC18090 and KC20176), and the Xuzhou Innovation Capacity Building Project (KC18241).

\section{References}

[1] M. C. He, H.-P. Xie, S.-P. Peng, and Y.-D. Jiang, "Study on rock mechanics in deep mining engineering," Chinese Journal of Rock Mechanics and Engineering, vol. 24, no. 6, pp. 28042814, 2005, in Chinese.

[2] F.-Q. Gong, J.-Y. Yan, S. Luo, and X.-B. Li, "Investigation on the linear energy storage and dissipation laws of rock materials under uniaxial compression," Rock Mechanics and Rock Engineering, vol. 52, no. 12, pp. 4237-4255, 2019.

[3] F. Gong, J. Yan, X. Li, and S. Luo, "A peak-strength strain energy storage index for rock burst proneness of rock materials," International Journal of Rock Mechanics and Mining Sciences, vol. 117, pp. 76-89, 2019.

[4] Y.-L. Zhao, L.-Y. Zhang, J. Liao, W.-J. Wang, Q. Liu, and L. M. Tang, "Experimental study of fracture toughness and subcritical crack growth of three rocks under different environments," International Journal of Geomechanics, vol. 20, no. 8, Article ID 4020128, 2020.

[5] K. Peng, J. Zhou, Q. Zou, Y. Zhang, and G. Tan, “Deformation characteristics and failure modes of sandstones under discontinuous multi-level cyclic loads," Powder Technology, vol. 373, pp. 599-613, 2020.

[6] K. Peng, Z. Liu, Q. Zou, Q. Wu, and J. Zhou, "Mechanical property of granite from different buried depths under uniaxial compression and dynamic impact: an energy-based investigation," Powder Technology, vol. 362, pp. 729-744, 2020.

[7] K. Peng, J. Zhou, Q. Zou, and X. Song, "Effect of loading frequency on the deformation behaviours of sandstones subjected to cyclic loads and its underlying mechanism," International Journal of Fatigue, vol. 131, Article ID 105349, 2020.

[8] W.-L. Jin and Y.-X. Zhao, "State of the art on durability of concrete structures," Journal of Zhejiang University (Engineering Science), vol. 36, no. 4, pp. 371-274, 2002, in Chinese.

[9] X.-Y. Shang and H. Tkalčić, "Point-source inversion of small and moderate earthquakes from $\mathrm{p}$-wave polarities and $\mathrm{p} / \mathrm{s}$ amplitude ratios within a hierarchical bayesian framework: implications for the geysers earthquakes," JGR: Solid Earth, vol. 125, no. 2, Article ID e2019JB01849, 2020.

[10] J. P. Forth, "Predicting the tensile creep of concrete," Cement and Concrete Composites, vol. 55, pp. 70-80, 2015.

[11] C.-J. Xia, Z.-H. Chen, K. Chen, and K. Chen, "Comparison of creep models for early-age concrete," Journal of Civil, Architectural \& Environmental Engineering, vol. 38, no. 1, pp. 61-68, 2016, in Chinese.

[12] B. Li, H. Yin, X. Mao et al., "Macroscopic and microscopic fracture features of concrete used in coal mine under chlorine salt erosion," International Journal of Mining Science and Technology, vol. 26, no. 3, pp. 455-459, 2016.

[13] Z. Zhao, K. Wang, D. A. Lange, H. Zhou, W. Wang, and D. Zhu, "Creep and thermal cracking of ultra-high volume fly ash mass concrete at early age," Cement and Concrete Composites, vol. 99, pp. 191-202, 2019.

[14] H.-L. Lv and G.-X. Cui, "Study on the coupling mechanism between reinforced concrete shaft lining and thick surrounding rock (soil)," Journal of China Coal Society, vol. 26, no. 5, pp. 501-506, 2001, in Chinese.

[15] C. Zhang, W.-H. Yang, J.-H. Liu, Z.-C. Wei, and H.-P. Li, "Construction technology and monitoring analysis on 
concrete strain of a new single-layer shaft lining in deep aqueous bed rock during freeze sinking," Journal of China Coal Society, vol. 37, no. 2, pp. 192-199, 2012, in Chinese.

[16] Y.-F. Gao, K.-M. Liu, H. Xie, K.-P. Gao, B.-H. Chen, and F.-Y. Zhang, "Steel tube concrete support applied to dynamic pressure roadway in kilometers deep mine," Coal Science and Technology, vol. 43, no. 8, pp. 7-11, 2015, in Chinese.

[17] B. Li, L.-Y. Zhang, Y. Li, H.-G. Yin, and R.-X. Liu, "Stepwise loading-unloading creep testing of fly ash concrete and its constitutive model," Thermal Science, vol. 23, no. 3, pp. 1539-1545, 2019.

[18] W. Lu, B. Jiang, Q. Wang, H.-B. Sun, Y. B. Huang, and P. Zhang, "Mechanical characteristics and parameter influencing mechanism of square steel confined concrete arch components in deep soft rock roadway," Journal of Mining \& Safety Engineering, vol. 37, no. 3, pp. 473-480, 2020, in Chinese.

[19] A. M. Neville, W. H. Dilger, and J. J. Brooks, Creep of Plain and Structural Concrete, Construction Press, Amsterdam, Netherlands, 1983.

[20] R. S. Ghosh and J. Timusk, "Creep of fly ash concrete," ACI Journal Proceedings, vol. 78, no. 5, pp. 351-357, 1981.

[21] G.-X. Huang, R.-Y. Hui, and X.-J. Wang, Creep and Shrinkage of Concrete, China Electric Power Press, Beijing, China, 2011, in Chinese. 